\title{
AMAZÔNIA E MARX NA PERIFERIA LATINO-AMERICANA
}

\author{
AMAZONIA Y MARX EN LA PERIFERIA LATINOAMERICANA
}

\section{AMAZON AND MARX IN LATIN AMERICAN PERIPHERY}

DOI: http://dx.doi.org/10.9771/gmed.v13i2.45049

\author{
Rita de Cassia Fraga Machado ${ }^{1}$ \\ Luiz Fernando de Souza Santos²
}

Resumo: O presente trabalho tem por objetivo explorar a hipótese de um encontro entre Karl Marx e o mundo tropical que chamaremos de Amazônia. Exploraremos uma hipótese de David Harvey, que indica a presença de uma espacialidade, uma territorialidade na mobilização de categorias de valor-de-uso e valor-de-troca para indicar a exigência da Amazônia, considerando a América Latina.

Palavras-chave: Amazônia. Marx.O capital. América Latina.

Resumen: El presente trabajotiene por objetivo explorar lahipótesis de unencuentro entre Karl Marx y el mundo tropical que llamaremos de Amazonia. Exploraremos una hipótesis de David Harvey, que indica la presencia de una espiritualidad, una territorialidadenlamovilización de categorías de valor-de-uso y valor-de-cambio para indicar laexigenciadel Amazonas, considerando la América Latina.

Palabras clave: Amazonía, Marx. El Capital. América Latina.

Abstract: The presentworkaimsto explore thehypothesisof a meeting between Karl Marx andthe tropical world thatwewillcalltheAmazon. Wewill explore a hypothesisby David Harvey, whichindicatesthepresenceof a spatiality, a territoriality in themobilizationof use-valueandexchange-valuecategoriestoindicatetherequirementoftheAmazon, consideringLatinAmerica.

Keywords:Amazon; Marx. The capital. LatinAmerica.

\section{Introdução}

Sem a pretensão de querer esgotar as reflexões em torno da hipótese do encontro entre Marx e o mundo tropical, cumpre ressaltar que aqui serão expostos os sentidos das marcas desse evento intelectual. Como haveria de ser com o principal autor do materialismo histórico-dialético, esse encontro não se deu numa relação positivista do tipo sujeito-objeto. As referências ao mundo além da Europa, em Marx, não são apenas para confirmar sua teoria. Os trópicos cumpriram um papel de elemento de explicação heurística, que objetaram ao autor, obrigando-o a refinar seu arcabouço conceitual.

Ao cotejarmos as publicações em língua portuguesa de $O$ capital com a língua na qual foi originalmente escrito, podemos observar o método de exposição de Marx, em nome do rigor teórico, em mobilizar palavras que indicam as marcas dos trópicos no seu texto; marcas que ficaram apagadas nos esforços dos tradutores por oferecer a referida obra na língua de Machado de Assis. Mas, além das 
palavras, há outras marcas da presença tropical em Marx, a saber: ao discorrer sobre a teoria do valor e recorrer a categorias como trabalho, processo de valorização, valor-de-uso, valor-de-troca, produção, circulação, entre outras, ele nos apresenta uma pluralidade de manifestações fenomênicas, expressões histórico-materiais destas, que remetem ao mundo tropical, ao continente latino-americano.

No presente trabalho, exploraremos esse encontro do Mouro de Trier com o mundo tropical, obedecendo a um roteiro de exposição que toma como ponto de partida notas de escritos diversos de Marx que contradizem certas correntes de debate contemporâneas, as quais veem nele um autor fundamentalmente eurocêntrico. Em seguida, apontaremos na obra $O$ capital, livro I, um exercício de cotejamento com a língua alemã que buscará indicar que, ao fazer uso de palavras como urwald, unwäldler, erde, jungfräulicheerde, Marx expressa o impacto dos trópicos no pensamento alemão. Por fim, exploraremos uma hipótese de David Harvey, que indica a presença de uma espacialidade, uma territorialidade na mobilização de categorias como valor-de-troca, valor-de-uso, valor etc., para indicar a exigência da consideração da América Latina, mais especificamente da Amazônia latino-americana para melhor apreendermos tais categorias.

\section{Marx para além da Europa e do eurocentrismo: a Amazônia}

Ao discorrer sobre Simon Bolívar, Marx, segundo Aricó, tratou-o de modo bastante depreciativo: o "canalha mais brutal, covarde e miserável” (MARX, apud ARICÓ, 1982, p. 97). Essa visada em torno de Bolívar seria um desdobramento de uma apreciação política de Marx, que vê nele os traços típicos do autoritarismo bonapartista que observava na França. Mais ainda: essa apreciação seria a expressão da incompreensão sobre a América Latina e o seu movimento histórico efetivo. Isso se explicaria pela presença marcante de uma compreensão hegeliana do processo histórico.

Aricó lembra que há no raciocínio hegeliano a compreensão de que a história seria a manifestação da "racionalidade do vir a ser" (ARICÓ, 1982, p. 104) e que, pois, os povos com destino histórico seriam aqueles capazes de elaborar a síntese das diversas formas particulares e contingentes que emergiram ao longo do desenrolar da história. Não é o caso dos povos latino-americanos, presos do acaso e das contingências. Mergulhados na irracionalidade, esses povos seriam "sem história".

O caráter depreciativo da abordagem de Marx sobre Bolívar, então, decorreria de um acento hegeliano que o levaria a considerar os feitos deste como consequência da contingência, de acontecimentos fortuitos, nos quais há a ausência de uma perspectiva fundada na luta de classes que seja a fonte de sentido dos processos latino-americanos. Sem essa fonte, "Marx se viu obrigado [a] recolocar a noção, sempre presente no fundo do seu pensamento, de 'povos sem história"' (ARICÓ, 1992, p. 105106). ${ }^{3}$ Essa disposição marxiana em relação a Bolívar repercutirá entre os americanistas soviéticos e se desdobrará, na primeira metade do século XX, numa caracterização negativa, pela Terceira Internacional, das lutas pela independência no continente latino-americano. 
Desse tipo de abordagem pode-se facilmente concluir, como o fizeram os teóricos dos estudos pós-coloniais, que se está diante de um Marx, com rebatimentos no marxismo, fundamentalmente eurocêntrico. Todavia, José Aricó aponta numa outra direção. Ao tratar das falácias em torno de uma disposição eurocêntrica em Marx, Aricó registra que este, ao chegar a Londres, passará a refletir de forma mais constante sobre o mundo não europeu. Os acontecimentos que sacudiram a Europa entre os anos de 1848 e 1850 levaram o pensador alemão a ter como ponto de partida a compreensão de que a Inglaterra seria o elo central, o demiurgo, do cosmos burguês (ARICÓ, 1982, p. 93). Mas, a partir de 1850, os estudos de Marx passam a se desdobrar em três grandes linhas: a análise da sociedade capitalista, o mercado mundial e as relações diplomáticas internacionais, que se articulam no esforço para uma interpretação da vida econômica que passa a reger a vida moderna. É aí que o mundo além da Europa ganha maior frequência nas reflexões marxianas, que dilatam assim o já referido cosmos burguês.

No entanto, observa Aricó, a formação do movimento socialista no século XIX se inspirou em obras de Marx e Engels que, cada uma a seu modo, se envolveram com a tese presente em $O$ capital de que a região industrialmente mais desenvolvida é a chave para a interpretação do futuro das menos desenvolvidas. Desse modo, o Manifesto do Partido Comunista, a Contribuição à crítica da economia política, O capital, tomo I, e o Anti-Düring apenas reforçariam a ideologia que esses movimentos socialistas irão denominar "marxismo" (ARICÓ, 1982, p. 48-50) e que compreendia o desenvolvimento econômico como um movimento que levaria inevitavelmente os diversos países a percorrerem o mesmo percurso histórico até as formas mais desenvolvidas. Quando são publicadas as obras de Marx e Engels que ampliam o escopo de suas abordagens do capitalismo para uma escala mundial, em que a Irlanda, a Rússia, a Espanha, entre outros, passam a ter um lugar mais importante no conjunto de suas reflexões, vão encontrar um ambiente ideológico e cultural no qual o marxismo "não estava preparado para compreender a sua verdadeira significação" (ARICÓ, 1982, p. 49).

Essa disposição do marxismo, se refletida em relação à América Latina, é acentuada ainda, como observado acima no tratamento dispensado a Simon Bolívar, pelo "desencontro", pela "omissão", pela “ausência” de reflexão, pelo "descuido” de Marx com esse continente. ${ }^{4}$ Ao lidar com outras regiões além da Europa ocidental ou daquelas representativas das formas clássicas das revoluções burguesas, no entanto, Marx ampliará o cosmos burguês numa direção em que percebe que é próprio do capitalismo uma história que se desenvolve de modo desigual e descontínuo. Dessa forma, conforme Aricó,

[...] torna-se seriamente enfraquecida a ideia de um epicentro da revolução que daria sentido ao conjunto do movimento social de libertação dos explorados, o qual, consequentemente, começa a ser percebido e revalorizado pela positividade de sua posição excêntrica ao proletariado europeu ocidental. (ARICÓ, 1982, p. 76)

Isso implica, para Aricó, que o eurocentrismo em Marx está superado na medida em que ele evita pensar a emancipação dos povos dominados nos limites exclusivos do desenvolvimento capitalista e de uma classe revolucionária operária homogênea. Assim, em relação à América Latina, estão dadas no pensamento marxiano as premissas para pensar sua autonomia, e é um engano considerar o desencontro deste com aquela em razão dos componentes eurocêntricos que lhe seriam imanentes (ARICÓ, 1982, p. 
78-79). Porém, não é dessa forma que o movimento socialista expresso na II Internacional e na III Internacional compreenderá os povos na periferia do capitalismo e da revolução bolchevique. O que sobressairá é um Marx com uma visada teleológica da história, bem ao estilo da reflexão que vê na anatomia do ser humano a explicação para a do macaco, e na qual a Europa é a expressão do vir a ser das outras regiões. O que soa paradoxal, se lembrarmos que a revolução bolchevique ocorreu em solo russo e no qual Marx também viu as marcas de uma história não linear, desigual, não evolucionista e não etapista.

Na publicação Lutas de classes na Rússia (2013), que reúne escritos de Marx e Engels produzidos entre 1875 e 1894, encontra-se uma compreensão dos eventos na Rússia que é bem diferente da visada fundada na noção de "povos sem história", como podemos conferir no texto de Engels a seguir:

Aqui estão reunidas todas as condições para uma revolução, que pode ser deflagrada pelas classes mais altas da capital, talvez até pelo próprio governo, mas que tem de ser levada rapidamente adiante pelos camponeses para além da primeira fase constitucional; uma revolução que será da maior importância para toda a Europa, uma vez que destruirá de um só golpe a última reserva ainda intacta do reacionarismo europeu como um todo. Essa revolução seguramente está a caminho. (MARX; ENGELS, 2013, p. 56)

Sobre a Rússia, na "Carta à Redação daOtechestvenyeZapiski”, de 1877, Marx assim se posiciona:

Quando se estuda cada uma dessas evoluções à parte, comparando-as em seguida, pode-se encontrar facilmente a chave desse fenômeno. Contudo, jamais se chegará a isso tendo como chave-mestra uma teoria histórico-filosófica geral, cuja virtude suprema consiste em ser supra-histórica. (MARX; ENGELS, 2013, p. 69)

Em texto introdutório a Lutas de classes na Rússia, intitulado "Dialética revolucionária contra a ideologia burguesa do progresso", Michael Löwy assinala que esses escritos de Marx e Engels têm o sentido de uma virada metodológica de ambos, ao admitir que as transformações sociais revolucionárias podem emergir na periferia do sistema capitalista, ao contrário de alguns escritos anteriores seus, os quais propunham que tais revoluções viriam do centro.

Marx e Engels não eram profetas, e suas previsões nada tinham de infalível. O curso real do processo histórico é sempre novo e imprevisível. Mas o conjunto de escritos sobre a Rússia nos anos 1877-1894 sugere uma hipótese que rompe com o economicismo, o eurocentrismo e o "progressismo" evolucionista: as revoluções sociais poderiam começar não nos países industrializados, nas grandes metrópoles (como se a história fosse uma laranjeira), mas na periferia do sistema capitalista, nos países "atrasados" - "semifeudais", "coloniais" e semicoloniais", ou "subdesenvolvidos", segundo uma terminologia do século XX. Esta hipótese sim é que se realizou no curso do século XX, desde a Revolução Russa de 1917 até a Cubana de 1959-1961. (LÖWY, 2013, p. 16)

Em carta a Kugelmann de 29 de novembro de 1869, portanto alguns anos antes dos escritos sobre a Rússia, Marx refletiu sobre a questão da Irlanda nos desdobramentos de sua emancipação social como condição para potencializar uma revolução operária na Inglaterra.

Qualquiermovimiento popular enla própria Inglaterra queda paralisado por lacontroversia com los irlandeses que, en Inglaterra, constituyen una fracciónmuy importante de laclaseobrera. Es imposiblecrearaquí LA PRIMEIRA CONDICIÓN para lograr laemancipación - elderrocamiento de laoligarquíalatifundista - porque no se podrá expugnar laplazaaquí, mientras em Irlanda losproprietarioslatifundistasmantengnan em sus manos sus puestos de avanzadas. (MARX, 1975, p. 144) 
Mas, se as premissas fundamentais para uma análise do capitalismo, considerando-o em termos históricos descontínuos bem diferentes de uma filosofia geral da história de acento teleológico, podem ser encontradas em Marx, por que, quando se deteve sobre a América Latina, é possível perceber um desencontro? Por que, para ficarmos nos termos de Aricó, Marx não prestou atenção ou foi em certa medida indiferente "diante da natureza específica, própria das sociedades latino-americanas no mesmo momento em que empreendia a complexa tarefa de determinar a especificidade do mundo asiático ou, mais exatamente, as formações não capitalistas típicas" (ARICÓ, 1982, p. 34)?

Há uma determinação histórica a ser levada em conta no que diz respeito à relação entre o pensamento de Marx e a América Latina. Trata-se, segundo Aricó, do seu antibonapartismo, que o levou a fazer uso da noção hegeliana de povos sem história - que, como observamos, já estava superada em sua análise ampliada do cosmos burguês, na qual havia a consideração da história descontínua do capitalismo - para suas considerações sobre o continente em questão. Em 1851, Marx publica O 18 Brumário de Luís Bonaparte, obra que dá conta de explicar as "circunstâncias e condições que permitiram a um personagem medíocre e grotesco desempenhar o papel de herói" (MARX, 2011, p. 18). Essa personagem, Carlos Luís Napoleão Bonaparte, Napoleão III, a quem Marx também chamou de aventureiro de "traços triviais e repulsivos" (MARX, 2011, p. 27), será responsável por lançar a França na disputa pela hegemonia entre as nações capitalistas europeias sobre aquelas que desencadearam o processo de independência no continente latino-americano e se libertaram politicamente de Espanha e Portugal.

Para se contrapor à noção de "hispanidade", que servira de argamassa ideológica das metrópoles ibéricas, Napoleão III procurará legitimar sua política externa para as nações do continente americano evocando uma suposta missão que fora destinada aos franceses de proteger as sociedades latinas. Num cálculo ideológico que dá fundamento à estratégia francesa de poder político, econômico e cultural sobre as ex-colônias espanholas e portuguesas, é então que será ressaltado o caráter latino delas. Essas nações disputadas pela França, no esforço para romper com o passado colonial e de resistir aos avanços dos Estados Unidos, vão assumir essa designação de "latinas". É nesse contexto que Aricó empreende o esforço de situar o desencontro de Marx com a América Latina. A indiferença, o descuido, de Marx em relação aos países latino-americanos e que se expressa bem no tom depreciativo que usa ao se referir a Simon Bolívar, mais do que uma disposição eurocêntrica, assinala Aricó, decorre de sua rejeição ao projeto bonapartista.

Bruno Bosteels (2013), que analisou os argumentos de José Aricó sobre o desencontro de Marx com a América Latina, considerou que a reflexão deste último decorre do que considera característico da história dos conceitos, a saber, que em diversos estudos sobre política, arte ou cultura há a presença de um não dizer que é resultado de omissões propositais ou de deslizes inconscientes (BOSTEELS, 2013, p. 13). Em Marx mesmo, nesse desencontro com o continente latino-americano, há, conforme o raciocínio de Aricó, esse não dizer que estaria assentado no antibonapartismo do pensador alemão. Residiria aí a origem da ausência, da omissão, de uma abordagem outra da América Latina que já existiria em potência na visada marxiana sobre o desenvolvimento histórico como não linear. Citando Álvaro García Linera, Bosteels 
ressalta que Aricó exercita também o não dizerer ao ignorar que as omissões de Marx em relação a esse continente decorrem efetivamente da escassez de informações deste sobre as lutas de resistência das sociedades indígenas e, acrescentemos, dos escravos trazidos da África e dos estratos brancos empobrecidos que foram mandados para cá. Além disso, tais lutas não estariam generalizadas por todo o continente no momento em que Marx desenvolveu suas reflexões sobre ele. Assim, não é a uma posição política antibonapartista, ou a uma angulação filosófica hegeliana que vê a América Latina como lugar de povos sem história, que se deve atribuir os fundamentos dessa "lógica de desencontro". Dessa forma, o não ver, o não dizer, marxiano é antes uma consequência de um não ver, um não dizer, de Aricó quando analisa o primeiro. "El terreno enel que Aricó nos coloca no es el de larealidadniel de lasherramientas de Marx para comprender esta realidad sino más bienel de larealidad que Aricócree es y de lasherramientas que Aricócreesonlas de Marx” (GARCÍA LINERA, apud BOSTEELS, 2013, p. 16).

Domenico Losurdo, em A luta de classes: uma história política e filosófica (2015), ao analisar as referências de Marx e Engels fora do eixo da Europa ocidental, chama a atenção para um desdobramento do método de exposição destes, a saber, que, como no caso da Irlanda, não é possível existir uma "questão social" descolada da "questão nacional", ambas estão em relação de identidade. "A 'questão social' é, nesse caso, a categoria mais geral, o gênero, que na situação concreta da infeliz ilha, há séculos explorada e oprimida pela Grã-Bretanha, se apresenta sob a espécie de 'questão nacional”' (LOSURDO, 2015, p. 28). Em O Manifesto Comunista, Miséria da filosofia, Grundrisse, A ideologia alemã e Trabalho assalariado e capital, Losurdo encontrará Marx e Engels a assinalarem que a exploração a qual o proletariado está submetido no interior de uma nação é a expressão da exploração de uma nação em relação à outra, o que significa então, que:

Longe de ter pouca relevância do ponto de vista da luta de classes, a exploração e a opressão que se desenvolvem em âmbito internacional são uma precondição, pelo menos no plano metodológico, para a compreensão do conflito social e da luta de classes em âmbito nacional. (LOSURDO, 2015, p. 26)

No escopo de tal raciocínio, o pensador italiano avança questões que apontam para a luta de classes além daquela desenvolvida pelo "trabalhador livre": os "negros revoltosos do Haiti" bem como os escravos "fugidos de todas as colônias", referidos em A ideologia alemã, não estariam a realizar a luta de classes? Luta de classes é compreendida aqui em sentido amplo, e as lutas das nacionalidades oprimidas, pois, têm nexo com as lutas de classes. Dessa forma, as questões nacionais além da Europa ocidental têm papel fundamental na elucidação da estrutura do modo capitalista de produção e das relações de exploração e dominação entre as nações do centro e da periferia. Uma visada fundamentalmente eurocêntrica não seria capaz de vislumbrar e, mais ainda, de tomar como fundamento metodológico a explicação da luta de classes no sentido amplo em que Marx e Engels a compreenderam.

A partir dessas, podem-se notar a crítica e as viradas teóricas promovidas pelo filósofo alemão, que ocorrem por sua imanência nas contradições do presente, numa oposição à disposição de um conhecimento que se apresenta como neutro, distante e externo aos fenômenos que observa. Já na primeira metade dos anos de 1840, quando rompe com os novos hegelianos de esquerda, "Marx diz não 
querer antecipar dogmaticamente o novo mundo, mas encontrá-lo a partir da crítica do antigo" (TIBLE, 2013, p. 17). Esse ainda é um debate interno ao pensamento europeu daquele período, mas já contém uma premissa importante para o encontro do ponto de vista marxiano com as sociedades não ocidentais, inclusive as ameríndias, que é o cultivo de uma reflexão não dogmática. Isso, de acordo com Tible, propiciará que a recepção das descobertas antropológicas se faça acompanhar de um forte impacto em Marx. Assim, ao fazer anotações sobre os estudos de Lewis Morgan sobre as sociedades iroqueses e outros povos tribais, tem contato efetivo com organizações societárias sem classes que, conforme infere Tible, são pensadas em suas implicações revolucionárias e repercutem no seu modo de pensar. Engels, numa carta enviada à Kautsky em abril de 1884, assim explicita o impacto desse encontro:

Para nossa visão global, penso que essa coisa tem uma importância especial. Morgan nos permite olhar para as coisas a partir de novos pontos de vista, fornecendo-nos com a história pretérita delas uma base que nos faltava (ENGELS, in MARX; ENGELS, 1979 [1888-1887], p. 142). ${ }^{5}$

Essa disposição não dogmática, aberta para se deixar envolver pelo novo e, a partir dele, pôr o pensamento em movimento por uma angulação nova, se desdobra num conjunto de contribuições do marxismo para pensar as sociedades indígenas na América Latina. Tible nos lembra a contribuição de Rosa Luxemburgo que, visando a crítica do capitalismo, no livro Introdução à economia política utiliza grande parte de suas reflexões para dar conta dos impactos das descobertas antropológicas relativas às sociedades indígenas. $\mathrm{O}$ mesmo ocorre com o pensamento de diversos autores da tradição marxista, que encontrarão nos povos indígenas a inspiração para pensar a sociedade sem classes posta no horizonte do comunismo. Conforme Tible, a partir do continente latino-americano, Mariátegui escreverá uma página essencial do encontro do marxismo com os povos ameríndios. Ao trabalhar a questão indígena como elemento fulcral no debate marxista no continente, o pensador peruano rejeita o ponto de vista eurocêntrico e também aquele que se prende ao excepcionalismo das sociedades ameríndias. Dessa forma, promove uma espécie de indigenização do pensamento de Marx para o marxismo latino-americano, pois não se deixa levar de modo exclusivo pela perspectiva europeia, uma vez que se permite, no encontro com a questão indígena, inquietar-se e pensar teoricamente fora dos quadros de um pensamento dogmático.

\section{O capital e mundo tropical}

Em O capital, Marx foi impactado pelo mundo tropical, quer seja na construção do argumento conceitualmente mais sólido, quer seja na exposição da anatomia do capital em seus nexos espaçotemporais, como procuraremos demonstrar nesta seção e na seguinte.

No capítulo V, "O processo de trabalho e o processo de valorização", percebemos as marcas desse encontro com o Novo Mundo na exposição marxiana sobre o trabalho como um processo a ser considerado "independentemente de qualquer forma social determinada" (MARX, 2013, p. 255). Marx inicia a análise assinalando que o ponto de partida essencial é que o trabalho é um processo que determina a relação metabólica do ser humano com a natureza - entendida esta última como sua própria corporeidade e a natureza que lhe é exterior e objeto de sua ação. Mas essa atividade, para corresponder ao 
significado categórico de trabalho, já não é determinada por uma disposição instintiva, animal, de seu agente. O trabalho é relativo exclusivamente ao ser humano que, além de sua corporeidade, coloca em movimento uma vontade em relação a um fim. Essa vontade, por sua vez, ao lado do objeto e dos meios de trabalho, compõe os momentos simples desse processo. Ao discorrer sobre os objetos de trabalho preexistentes, Marx assinala o seguinte:

A terra (que do ponto de vista econômico, também inclui a água), que é para o homem uma fonte originária de provisões, de meios de subsistência prontos, preexiste, independentemente de sua interferência, como objeto universal do trabalho humano. Todas as coisas que o trabalho apenas separa de sua conexão imediata com a totalidade da terra são, por natureza, objetos de trabalho preexistentes. Assim é o peixe, quando pescado e separado da água, seu elemento vital, ou a madeira que se derruba na floresta virgem $^{6}$ ou o minério arrancado de seus veios. (MARX, 2013, p. 256)

No capítulo VI, "Capital constante e capital variável”, ao se referir a meio de produção que não transfere valor, portanto, é somente elemento para a produção de valor-de-uso, Marx aponta os "meios de produção que preexistem na natureza sem a intervenção humana, tais como a terra, o vento, a água, o ferro nos veios das rochas, a madeira nas florestas virgens etc" (MARX, 2013, p. 281). ${ }^{8}$

O capítulo XXIII, “A lei geral da acumulação capitalista”, na nota de rodapé 70, é esclarecedor: Marx distingue o proletário (Proletarier), aquele que produz valor, do selvático (Urwäldler), que tem uma relação de propriedade com a floresta. Considerar que este último é um proletário da floresta é não ter compreendido o sentido da relação que ele estabeleceu com a floresta e nem o que ela seja.

Nessas passagens ao longo de $O$ capital, podemos perceber os impactos no pensamento ocidental do encontro com o continente americano, e que a tradução para o português obstaculiza a apreensão. É que traduzir urwald, do alemão, para "florestas virgens" comporta uma grande imprecisão e silêncios sobre as exigências que as regiões tropicais ameríndias impuseram ao pensamento europeu para expressá-las. Urwald não é uma palavra que se encontra na língua alemã antiga (alterdentsches). Para o europeu, a experiência concreta com o meio natural até o encontro com o Novo Mundo são os bosques já profundamente antropizados, que em alemão são expressos por wald e/ou wälder(a partir daqui só nos referiremos à primeira), palavras que sempre carregam o sentido de florestas marcadas pela intensa atividade humana. Quando Marx trabalhou como jornalista na Gazeta Renana e escreveu sobre o conflito com lenhadores no Vale de Mosela, ou quando, no capítulo sobre a acumulação primitiva, em O capital, comenta sobre as florestas de caça que foram reservadas para o lazer dos nobres, nesses dois momentos entendemos que o argumento marxiano se vale do sentido posto em wald: trata-se de ambientes de indisfarçável impacto humano.

No entanto, com a divulgação na Europa, ao longo do século XVIII, das "descobertas" resultantes das viagens dos naturalistas, os conceitos do pensamento ocidental para se referir ao ser humano e a natureza são profundamente abalados. Buffon, De Paw, Spix e Martius, Von Humboldt, entre outros, trazem notícias de um mundo que não se deixa apreender pelo sentido dado em wald. Segundo Hans ChristophBuch, em " No one wanders under palm trees unpunished.'Goethe and Humboldt" (2012), Humboldt retira a ideia de uma floresta primordial do tempo e a insere no pensamento em termos 
antigos: "A floresta primitiva (em alemão 'urvald") é vista como um mundo antigo de um tempo préhistórico, como um mundo onde o tempo está suspenso" (BUCH, 2012, p. 285).9 Mary Louise Pratt, em "Humboldt e a reinvenção da América"(1991), assinala que, efetivamente, o que Humboldt promove em seus trabalhos sobre o mundo tropical é uma articulação entre a exposição científica e uma estetização de raízes românticas em torno do sublime. Nesse mundo, a grandeza da natureza evoca uma pretérita comunhão entre o meio natural e a vida espiritual do ser humano (PRATT, 1991, p. 155). Esse é um ambiente harmônico, não alienado, porém, desprovido de seres humanos (o que é um paradoxo, posto que a alienação é um produto de relações histórico-sociais). É a ausência de humanidade, exceto do viajante que narra sua potência, que permite à natureza desenvolver suas forças. Desse modo, em Humboldt tempo e espaço se excluem mutuamente no mundo tropical. "A ciência natural cataloga o mundo como natureza e especificamente não a cataloga como história” (PRATT, 1991, p. 156).

A natureza encontrada no continente americano, portanto, não tem paralelo no imaginário do europeu oitocentista e para designá-la, ao fim desse século e no XIX, passa-se a observar o uso da palavra wald acrescido do prefixo ur-, que dá o sentido de primordial, intocado, original. As florestas tropicais americanas, desse modo, estão na gênese da palavra urwald. ${ }^{10}$ Quando Marx, pois, faz o uso dela é para se referir a uma fonte de objetos de trabalho preexistentes que não se confunde com os bosques de Mosela ou aqueles destinados ao descanso e à diversão dos nobres ingleses. Não há nada parecido, em $O$ capital, com uma visada homogeneizante do espaço. O processo de trabalho, a relação metabólica do ser humano com a natureza são pensados nessa obra diante de múltiplas espacialidades e formas de organização da vida econômica, política e social, que o encontro com o Novo Mundo tornou incontornável pensar.

Observamos ainda que traduzir urwald por "florestas virgens" deve ser acompanhado, além da análise do contexto de emergência dessa palavra no pensamento alemão, por uma reflexão sobre o sentido particular com que ela é apreendida por Marx, pois nos parece que é bem distinto do significado dado pelas ciências da natureza, particularmente daqueles ramos de estudos ecológicos. Nas ciências ecológicas, urwald tem o sentido de natureza intocada, virgem, a ser protegida da presença humana. Em Marx, no entanto, conforme pode-se observar na passagem transcrita acima, urwald é fonte onde o ser humano encontra objetos preexistentes de trabalho. Mesmo que não tenha os efeitos de antropização dos bosques europeus, na arguição marxianaurwaldjá pressupõe a presença do sujeito cujo trabalho é um pôr teleológico. Esse sujeito é o unväldler da nota de rodapé 70, do capítulo XXIII, acima referida.

Entendemos, inclusive, que a escolha de Marx pelo uso das palavras urwald e urwäldlerconstitui uma das chaves que explicam o interesse dele pelos estudos etnológicos de Morgan, do qual, segundo Jean Tible (2013, p. 53-57), extrairá imensas passagens sobre a organização social, política e econômica de povos tribais do continente americano, os iroqueses em particular, e que irão compor os seus Cadernos etnológicos.

O capítulo V, de O capital, livro I, nos permite, também, assinalar que a Terra (Erde), como totalidade que comporta todos os objetos do trabalho, mesmo nos lugares em que não sofreu a intervenção humana, tem o seu sentido dado por essa presença, por esse "animal que faz ferramentas" 
(MARX, 2013, p. 257). Uma terra virgem (JungfräulicheErde) só é possível através de um exercício de abstração, de reconstrução histórica, até os tempos primeiros, quando o trabalho que se realiza como posição de finalidade concreta a toma pela primeira vez como objeto. Também, "terra virgem" é o experimento intelectual que Marx mobiliza no capítulo I, "A mercadoria”, para assinalar que uma coisa pode ter utilidade sem conter valor, sem que seja necessária a mediação do trabalho: "Assim é o ar, a terra virgem, os campos naturais, a madeira bruta etc.” (MARX, 2013, p. 118).

Cumpre observar, por fim, ainda no capítulo $\mathrm{V}$ de $O$ capital, livro I, que, para apresentar uma imagem de exceção, diferente dos ramos industriais típicos do mundo europeu, Marx faz referência a uma "indústria extrativa", cujo objeto de trabalho é dado imediatamente pela natureza, tal como a mineração, a caça, a pesca etc. Do exposto até aqui, permitimo-nos inferir que aquele que trabalha nessa indústria extrativa é o urwäldler, cuja tradução para a língua portuguesa toma como selvático. Da argumentação que Marx desenvolve no citado capítulo, urwäldler tem um sentido mais amplo do que a expressão reducionista de selvagem. Trata-se de um ser social que, em condições diferentes de trabalho, de relações diversas de propriedade, distintas da ordem capitalista, estabelece com a terra (Erde), com a floresta (urwald), uma mediação marcada pelo pôr teleológico, portanto, com o trabalho, que lhe permite regular e controlar seu metabolismo com o mundo natural.

\section{O capital e a Amazônia}

Nesta seção exploraremos brevemente, em Marx, a reflexão de David Harvey, no livro Os limites do capital (2013), sobre o fato de que a teoria do valor tem por domínio fundamental um espaço-tempo relacional. Isso significa que a mercadoria, para a realização do valor, precisa se deslocar no espaço-tempo das relações de troca. Ao fim e ao cabo, o capital cria um espaço-tempo à sua imagem e à sua semelhança que deságua numa espacialidade não homogênea, uma vez que algumas regiões concentram enorme contingente de forças produtivas, ao passo que outras estão distantes de tal condição, indicando um “desenvolvimento geográfico desigual do capitalismo” (HARVEY, 2013, p. 478).

Seguiremos as sugestões de Harvey tomando aqui o capítulo V, "O tempo de curso", do livro II, de $O$ capital. Nesse capítulo, Marx inicia pela abordagem do tempo total do movimento do capital. Ele estabelece aí a distinção entre a duração do capital no âmbito da produção e no da circulação. Desse modo, o ciclo total de seu movimento corresponde à somatória do tempo de produção ao tempo de circulação. O tempo é uma categoria explicativa fundamental nessa exposição, porém, no escopo da tradição do pensamento alemão que vai de Kant a Hegel, Marx a mobiliza em sua existência dialética com a categoria de espaço, conforme pretendemos explorar nesta seção.

Inicialmente, Marx analisa o tempo de produção, que engloba o tempo do processo de trabalho, mas não é por este englobado. Aponta que parte do capital constante presente nos meios de produção (máquinas, edifícios para estocagem de matéria-prima etc.) tem uma função ativa quando realiza-se como meios de produção, quando atua na produção, mas, também, tem momentos em que encontra-se inativo, 
por exemplo, quando o trabalho é interrompido no período noturno. Esse tempo de inatividade, que é parte do processo de produção, portanto, compõe o tempo de produção que, desse modo, é maior que o tempo de trabalho e o engloba. Um elemento fundamental a ser considerado em tais condições é o fato de que essa parte do capital constante que fica ociosa não produz mais valor, "não absorv[e] trabalho, tampouco absorv[e] mais-trabalho" (MARX, 2014, p. 203). A produtividade e a valorização de determinado capital produtivo investido num dado período só serão maiores, então, caso haja uma menor diferença entre o tempo de produção e o tempo de trabalho. Disso decorre a disposição da produção capitalista para criar as condições para uma maior coincidência entre o tempo de produção e o tempo de trabalho.

Ao analisar o tempo de curso, este é apreendido como o tempo que se leva para vender a mercadoria e converter o capital monetário em meios de produção e força de trabalho. O capital, pois, compreende dois processos na esfera da circulação: a metamorfose da forma-mercadoria em forma dinheiro (M-D) e a metamorfose da forma-dinheiro em forma-mercadoria (D-M). O tempo de curso, desse modo, é decomposto em: a) o tempo para o capital se transformar da condição de mercadoria em dinheiro, e b) o tempo a ser consumido na transformação em sentido contrário.

Marx observa que as operações M-D e D-M nem sempre ocorrem no mesmo espaço. Em sua fase D-M, o processo de circulação do capital corresponde à sua realização como capital produtivo num determinado investimento. Isso pode implicar a necessidade de investimento em meios de produção que não estão disponíveis nos mercados locais e devem ser buscados em mercados espacialmente distantes. É também possível que as duas operações, M-D e D-M, separadas no tempo, possam estar separadas no espaço, ou seja, o mercado de compra e o mercado de venda podem estar em espaços distintos. O capitalmercadoria M'-D', em face da forma existente da mercadoria como valor-de-uso, vê impostos certos limites à sua circulação, com claros desdobramentos no espaço e nos seres humanos que vivem nele.

É parte da natureza das mercadorias serem transitórias. Por isso, caso não se realizem no consumo, pelo capital produtivo ou pelo indivíduo, terão perdido suas propriedades como valores-detroca. A deterioração da mercadoria é o limite absoluto para o tempo de curso do capital-mercadoria. Quanto mais transitória for a mercadoria, mais rápido ela deve realizar o seu valor-de-troca,

tanto menos ela pode se distanciar de seu local de produção, mais estreita é sua esfera espacial de circulação e mais local é a natureza de seu mercado de escoamento. Assim, quanto mais transitória for uma mercadoria, quanto maiores forem, por suas qualidades físicas, os limites absolutos de seu tempo de curso como mercadoria, tanto menos ela é apta a ser objeto da produção capitalista. (MARX, 2014, p. 207)

As notas tomadas do capítulo sobre "o tempo de curso", em O capital, permitem-nos avançar aqui algumas digressões sobre a pesquisa de tese de doutoramento de Luiz Fernando de Souza Santos (2018) - que compreende a Amazônia como um artefato sócio-histórico-econômico-cultural construído pela aventura capitalista em seu processo de expansão para além dos limites da Europa -, as quais se assentam, conforme o exposto acima, no fato de que as operações M-D e D-M nem sempre ocorrem nos mesmos espaços e, também, por conta da transitoriedade de determinadas mercadorias. 
Nesse sentido, a borracha, cuja exploração na Amazônia tem seu auge em fins do século XIX e início do século XX, e que marca profundamente a história econômica da região, qual uma ferida narcisística, parece corresponder profundamente à análise marxiana sobre o tempo de curso do capitalmercadoria. Em face das demandas do capitalismo industrial pelo látex como matéria-prima, a região amazônica passa a ter um papel importante na sua produção. Todavia, da extração da seiva da seringueira até o preparo desse produto para chegar em vias de condições de consumo pelo capital produtivo na Europa, há uma grande transitoriedade. O que condena o trabalhador que faz a extração da seiva, o seringueiro, a uma vida prisioneira do espaço no interior da densa floresta.

E Euclides da Cunha, na obra À margem da história (1999), nos dá conta dos desdobramentos das demandas da produção capitalista pelo produto extraído da seringueira (Hevea Brasiliensis) no trabalhador responsável por tal extração:

homem constrangido a calcar durante a vida inteira a mesma "estrada", de que é ele o único transeunte, trilha obscurecida, estreitíssima e circulante, que o leva, intermitentemente e desesperadamente, ao mesmo ponto de partida. Nesta empresa de Sísifo, a rolar em vez de um bloco o seu próprio corpo - partindo, chegando e partindo - nas voltas constritoras de um círculo demoníaco, no seu eterno giro de encarcerado numa prisão sem muros, agravada por um ofício rudimentar que ele aprende em uma hora para exercê-lo toda a vida, automaticamente, por simples movimentos reflexos - se não o enrija uma sólida estrutura moral, vão-se-lhe, com a inteligência atrofiada, todas as esperanças, e as ilusões ingênuas, e a tonificante alacridade que o arrebataram àquele lance, à ventura, em busca da fortuna. (CUNHA, 1999, p. 22)

A Amazônia emerge neste confronto com o pensamento marxiano como resultante do desenvolvimento geográfico desigual do capitalismo, apontado por David Harvey. O seringueiro é parte produtor das condições de trabalho, salário e reprodução da existência do operariado europeu, é elemento encoberto no fetichismo da mercadoria do mundo industrializado em fins do século XIX e início do século XX.

\section{Como Síntese}

Desse modo, embora não encontre no capítulo objeto destas notas na presente seção a mesma preocupação de exposição que tem Marx, no livro I de $O$ capital, em proporcionar imagens tais quais às dos mortos que sugam o sangue dos vivos, da exploração dos trabalhadores na análise da jornada de trabalho ou sobre a sanguinária acumulação primitiva, é possível inferir da análise da totalidade do tempo do movimento do capital o modo como se efetiva em espaços longínquos dos centros e na gente que ali vive, que ali trabalha. Como é o caso do seringueiro na Amazônia no período aqui referido.

Por fim, nesse balanço das discussões sobre o encontro de Marx e do marxismo com as sociedades não ocidentais, fora do eixo europeu, consideramos uma outra contribuição fundamental, a saber, as reflexões de Jean Tible (2013) sobre o encontro de Marx com uma América ameríndia. 
O autor que usamos como referência para reflexão toma como fio condutor de nossas análises a relação íntima, em Marx, entre as lutas e a teoria se torna potência e a especificidade de seu pensamento residem no contato efetivo com as lutas de seu tempo que contribui pensar o tempo da Amazônia.

\section{Referências:}

ARICÓ, José. Marx e a América Latina. Rio de Janeiro: Paz e Terra, 1982.

BOSTEELS, Bruno. E1 marxismo en América Latina: nuevos caminhos al comunismo. La Paz: Vicepresidenciadel Estado Plurinacional/Presidencia de laAsamblea Legislativa Plurinacional, 2013.

BUCH, Hans Christoph. "No one wanders under palm trees unpunished." Goethe and Humboldt. In: CLARK, Rex; LUBRICH, Oliver. Cosmos and colonialism: Alexander von Humboldt in cultural criticism. New York: Berghahn Books, 2012.

GRIMM, Jacob; GRIMM, Wilhelm. DeutschesWörterbuch. Leipzig: Verlag S. Hirzel, 1971. Disponível em: http://woerterbuchnetz.de/DWB/. Acesso em: 20 mar. 2019.

CUNHA, Euclides. A margem da história. São Paulo: Martins Fontes, 1999.

HARVEY, David. Os limites do capital. São Paulo: Boitempo, 2013.

LOSURDO, Domenico. A luta de classes: uma história política e filosófica. São Paulo: Boitempo, 2015.

LÖVY, Michael. Dialética revolucionária contra a ideologia burguesa do progresso. In:MARX, Karl; ENGELS, Friedrich. Lutas de classes na Rússia. São Paulo: Boitempo, 2013.

MARX, Karl. O capital: crítica da economia política (livro I). São Paulo: Boitempo, 2013.

MARX, Karl. Das Kapital, Erster Band, Buch I, Werke 23. Berlim: DietzVerlag, 1962.

MARX, Karl. O capital (livro II). São Paulo: Boitempo, 2014. cap. V.

MARX, Karl. Cartas a Kugelmann. Habana, Cuba: Editorial de Ciências Sociales, 1975.

MARX, Karl. O 18 Brumário de Luís Bonaparte; São Paulo: Editorial Boitempo, 2011.

MARX, Karl; ENGELS, Friedrich. Lutas de classes na Rússia. São Paulo: Boitempo, 2013.

PRATT, Mary Louise. Humboldt e a reinvenção da América. Estudos Históricos, Rio de Janeiro, v. 4, n. 8, 1991, p. 151-165.

ROSDOLSKY, Roman. Friedrich Engels y el problema de lospueblos “sinhistoria”. México: EdicionesPasado y Presente, 1980.

SCHADE, Oskar. AltdeutschesWörterbuch.Zweiter Band. Halle (Alemanha): Buchhandlung des Waisenhauses, 1882.

SANTOS, Luiz Fernando de Souza. Entre o mágico e o cruel: a Amazônia no pensamento marxista brasileiro. 2018. Orientador:

Elide Rugai Bastos. 333 f. Tese (Doutorado) - Instituto de Filosofia e Ciências Humanas, Universidade Estadual de Campinas, Campinas (SP), 2018.

TIBLE, Jean. Marx selvagem. São Paulo: Annablume, 2013.

\footnotetext{
Notas

${ }^{1}$ Doutora em Educação pela Universidade Federal do Rio Grande do Sul (UFRGS). Professora de Filosofia da Universidade do Estado do Amazonas (UEM) e vice-coordenadora do Programa de Pós-Graduação em Educação do Amazonas (PPGE/UEA).
} 


Líder do grupo de pesquisa Movimentos sociais, feminismo e educação. Currículo Lattes:

http://lattes.cnpq.br/8882999172098781.Orcid: https://orcid.org/0000-0002-7385-3771 .E-mail: rmachado@uea.edu.br.

2 Doutor em Sociologia pela Universidade Estadual de Campinas (Unicamp). Professor do Departamento de Ciências Sociais, da Universidade Federal do Amazonas (UFA). Currículo Lattes: http://lattes.cnpq.br/3862781680822535 . Orcid: http://orcid.org/0000-0002-7251-5201 .E-mail: luizfernando@ufam.edu.br

${ }^{3}$ Roman Rosdolsky, no livro Friedrich Engels y elproblema de lospueblos "sinhistoria" (1980), analisa a presença dessa expressão em escritos de Engels sobre os eslavos da Áustria e da Hungria, a saber, checos, eslovacos, croatas, sérvios e ucranianos. Conforme Rosdolsky, povos sem história, em Engels, referiam-se aos "pueblos que ensupasado no consiguieroncrearningún sistema estatal vigoroso y de tal modo [...]ya no poseíanfuerzaalguna para obtenersu autonomia nacional enel futuro" (p.10). Diante de movimentos revolucionários no âmbito do desenvolvimento capitalista, esses povos sem história se posicionarão, na visada engelsiana, sempre de forma contrarrevolucionária. Rosdolsky assinala que trata-se de uma leitura de Engels com forte influência de uma leitura metafísica da história de corte hegeliano e que estava em contradição com a concepção materialista da história que desenvolvia ao lado de Marx. Somente com o austro-marxismo é que a expressão "povos sem história" se aclimatará à literatura marxista, mas com um sentido radicalmente distinto daquele apresentado por Engels, conforme podemos conferir em Otto Bauer, que assim entendia tal expressão: povos cuja "cultura nacional no conoceningunahistorianidesarrollo ulterior enaquella época en que las portadoras de tal cultura eram meramente lasclases dominantes" (BAUER,apud ROSDOLSKY, 1980, p. 130). "Sem história" tem, em Bauer, o sentido certeiro, segundo Rosdolsky, das condições de opressão a que estão submetidos vários grupos populacionais na Europa central e oriental nos séculos XVIII e XIX.

${ }^{4}$ As adjetivações para caracterizar a relação de Marx com a América Latina foram todas cunhadas por José Aricó.

5 "FürunsereGesamtanschauungwird das Ding, denkeich, besondereWichtigkeithaben. Morgan erlaubtuns, ganzneueGesichtspunkteaufzustellen, indemerunsmit der VorgeschichteeinebisherfehlendetatsächlicheGrundlagegibt" (traduçãolivre dosautores).

${ }^{6}$ Grifo nosso.

7 "Die Erde (worunterökonomischauch das Wassereinbegriffen), wiesie den Menschen ursprünglichmitProviant, fertigenLebensmittelnausrüstet, findetsichohneseinZutunals der allgemeineGegenstand der menschlichenArbeitvor. Alle Dinge, welche die Arbeitnur von ihremunmittelbarenZusammenhangmitdemErdganzenloslöst, sind von NaturvorgefundneArbeitsgegenstände. So der Fisch, der von seinemLebenselement, demWasser, getrennt, gefangenwird, das Holz, das imUrwaldgefällt, das Erz, das aus seiner Aderlosgebrochenwird” (Das Kapital, Erster Band, Buch I, p. 193).

8 "Produktionsmitteln, die von Natur, ohnemenschlichesZutum, vorhanden sin, mitErde, Wind, Wasser, demEisen in der Erzader, demHolze des urwaldesusw"(Das Kapital, Erster Band, Buch I, p. 193).

9"The "primeval forest" (in German 'urwald') is viewed as an ancient world of prehistoric time, as a world where time is arrested"(tradução livre do primeiro autor desse texto).

${ }^{10}$ Para essa discussão em torno das palavras wald, urwaldee do prefixo ur-, foram consultados AlterdeutschesWörterbuch(1882), de OskarSchade, e DeutschesWörterbuch (1954), de Jacob Grimm e Wilhelm Grimm. 